\title{
Passenger Car Equivalent Value for Commercial Vehicles: A New Approach
}

\author{
Efstathios Bouhouras ${ }^{1 *}$, Socrates Basbas ${ }^{1}$ \\ ${ }^{1}$ Laboratory of Transportation Planning, Transportation Engineering and Highway Engineering, Department of Transportation \\ and Hydraulic Engineering, School of Rural and Surveying Engineering, Faculty of Engineering, Aristotle University of \\ Thessaloniki, 54124 Thessaloniki, P. O. B. 54124, Greece \\ *Corresponding author, e-mail: stbouh@auth.gr
}

Received: 16 December 2019, Accepted: 11 March 2020, Published online: 07 June 2021

\begin{abstract}
Within the framework of the present paper an attempt has been made to develop a methodology for the calculation of a Passenger Car Equivalent (PCE) factor in order to express the number of commercial vehicles in the equivalent number of passenger cars. The methodology is based on the Highway Capacity Manual, the examination of the international literature and an extended field survey. The research area is the Municipality of Thessaloniki, Greece and specifically 27 at-grade, signalized intersections which were examined. The field survey was performed during two time-periods in order a comparison to be possible.
\end{abstract}

Keywords

Passenger Car Equivalent, Highway Capacity Manual, methodology, Thessaloniki

\section{Introduction}

The Passenger Car Equivalent factor (hereinafter mentioned as PCE) is a unit used in Transportation Engineering to express the number of vehicles other than passenger cars in an equivalent number of passenger cars. This is a critical value needed in order to calculate a number of traffic parameters by taking into account the total number of vehicles using the same transport infrastructure at the same time. The term "Passenger Car Equivalent" was firstly introduced in the 1965 U.S., Highway Capacity Manual (hereinafter mentioned as HCM) and defined as "the number of passenger cars displaced in the traffic flow by other transport modes under the prevailing roadway and traffic conditions" (Transportation Research Board, 2010). PCE values are usually used to convert heterogeneous traffic environment into homogeneous stream in which it is assumed that only passenger cars are traveling. PCE is derived from various characteristics of the traffic streams, such as headway, speed and volume along with vehicular and roadway characteristics (Ljubicic and Pavlovic , 2015).

The scope of this paper is to compare the value of PCE for commercial vehicles as it is provided by the HCM with the one which is developed in the central area of the city of Thessaloniki in the framework of the current research. The value of PCE for the commercial vehicles as provided by the HCM is 2.00. That means that each commercial vehicle in order to be expressed as passenger cars must be multiplied with the abovementioned value. However, even the slightest variance of this value could have an impact on the number of traffic parameters, often needed in the framework of a traffic study.

Firstly, a decision has been made about the methodology to be followed (HCM or a different one). For this to happen, the findings in the international literature were examined in order to identify the existing methodologies for the calculation of PCE value for commercial vehicles. During this process, another factor had to be taken into consideration and that was the selection of the appropriate hardware and software which are needed for this task. The next step concerned the identification of the study area and the design of the field survey. Finally, the analysis of the collected data in house and the necessary assumptions to be made were other crucial issues.

\section{Methodologies taken into consideration}

The first step of this process refers to the examination of the methodology described in Transportation Research Board (2010) and its lateral revised edition. It is beyond the scope of this paper to present the methodologies examined 
in full details. However, it must be mentioned at this point that these methodologies include the following:

- Highway Capacity Manual 2010

- Modified Density Method

- Multiple Linear Regression Model

- Method based on Headway

- Chandra's Method

- Density method

It must be noticed that a number of other methods were also taken into consideration as variations of the abovementioned ones. Each of these methods takes into consideration different traffic variables as the main parameters for the calculation of the PCE value. The following methodologies were based mainly on the correlation between the PCE value and the density of the vehicles along the road segment under study: St. John and Glauz (1976), Huber (1982), Mallikarjuna and Rao (2006), Demarchi and Setti (2003) and Rahman and Nakamura (2005). Another group of methodologies concerns the usage of headways as the main parameter for the calculation of the PCE value: Greenshields et al. (1947), Werner and Morrall (1976), Seguin et al. (1982), Cunagin and Chang (1982), Kimber et al. (1985) and Krammes and Crowley (1986). Another approach concerns the calculation of the PCE value based on the rate of the vehicles served in queue during a green light time period and that it could be minimum if only passenger vehicles are in queue as mentioned by Al-Kaisy et al. (2002) and Praveen and Arasan (2013). Finally, Skabardonis et al. (2014), highlighted the difficulty of the methodology proposed by the Transportation Research Board (2010) regarding the calculation of saturation flow in at-grade signalized intersections and concluded that the PCE value is dependent on the characteristics of the commercial vehicles, their percentage in the total amount of traffic and the vertical alignment of the road segments under study.

Based on the examination of the international literature, it was decided that the best approach would be to implement a methodology for the calculation of PCE based on headways. Therefore, direct field surveys had to be performed in order to collect the necessary data.

Taking into consideration this decision as well as the available human resources and software / hardware, it was decided that the study area should be the Municipality of Thessaloniki, Greece. This decision was based on the experience gained by previous research activities. It must be clarified at this point, that although the study area would be the Municipality of Thessaloniki, the field surveys concern specific at-grade signalized intersections which would satisfy the following parameters in the best possible way:

1. the main entry points ("gates") to the area of the Municipality of Thessaloniki should be included,

2. the primary road arterial network in the study area should be included,

3. the selected intersections must be characterized by significant volumes of commercial vehicles.

The specific traffic volumes should be recorded during the morning period since the Urban Road Freight Transport system in the Municipality of Thessaloniki does not allow goods distribution during the afternoon period. It must be mentioned that based on recent decisions of the Local Council of the Municipality of Thessaloniki, the distribution of goods is permitted during the night, while during daylight, there are restrictions regarding the weight of the commercial vehicles that are allowed to perform loading/ unloading activities ${ }^{1}$.

As a result, 27 at-grade signalized intersections were selected. These intersections have a total number of 51 legs and 169 lanes. The field surveys were planned to be performed in such a way that each lane of each leg in each intersection would be recorded 20 times for each green light phase. That means that overall, 3,177 green light phases were recorded with a total number of 16,000 vehicles. Regarding the data collection process a new methodology was implemented, with the aim to avoid the use of recording equipment if possible.

After examining the existing applications and tools that can be used for collecting traffic data, including headways, it was decided to use an application developed by JCT Consultancy Ltd located in the UK and specifically the JCT Traffic Tools which is provided free of charge and can be installed and used by any device with an Android (C) OS (above version 4.1). This choice allows the use of a smartphone or a tablet for data collection and at the same time to avoid the use of expensive and sensitive equipment such as video recorders (cameras). The detailed presentation of the selected application in full details is beyond the scope of this paper. It must be mentioned that

1 The official time period for goods distribution has been changed since the time the field counts took place; the new framework promotes night deliveries by excluding the goods distribution during daytime. It concerns vehicles not exceeding 1,5 tons payload (Decision No. 125 of the Council of Municipality of Thessaloniki, 2016). 
although the application records headways, it can also calculate saturation flows by using the UK's official PCE values for non-passenger vehicles (which are not editable). Therefore, it was decided that the PCE values would be calculated using the recorded headways and Eq. (1):

$E_{t}=\frac{\left(\frac{h_{m}}{h_{c}}\right)-P_{c}}{P_{t}}$,

where:

- $E_{t}=$ PCE value per lane per intersection leg

- $h_{m}=$ average value of recorded headways for all vehicles per lane per intersection leg concerning all 20 phases of green light

- $h_{c}=$ average value of recorded headways for passenger cars per lane per leg concerning all 20 phases of green light

- $P_{c}=$ percentage of passenger cars per lane per intersection leg

- $P_{t}=$ percentage of commercial vehicles per lane per intersection leg

The data collecting (recording) process presupposes the definition of a line vertical to the direction of vehicles' traffic movement, conceivable near the position of the traffic light through which the vehicles pass and which allows the surveyor to mark the time when each vehicle's front wheel passes this line. Data had to be collected for 20 consecutive time phases of green light for each lane and leg intersection. When the front tire of each vehicle was passing that conceivable line, the observer marked its passing time using the above-mentioned application. Furthermore, while waiting for the green phase to start, the observer had the ability to identify the number of vehicles waiting in queue and to record that number when the last vehicle went through the conceivable line. This was achieved by hitting the respective button on the application interface. The yellow (amber) light was the end of each recording period. In addition, all data were sent by mail to an account selected by the observer or, alternatively, saved in the smartphone's or tablet's memory.

The field surveys took place during May-June 2016, depending on the complexity of each intersection (number of legs, number of lanes per leg, etc.) from 07:00 to 14:00. Usually, the time needed for data collecting per intersection varied from two (2) to four (4) hours.

\section{Data analysis}

The data analysis revealed that it was necessary to define a threshold value concerning headways, above which the vehicles do not create congestion phenomena in order to identify which lanes per leg and per intersection are characterized by such conditions. Furthermore, it was clear that in those lanes operating in congested conditions the vehicles would use all the available green light.

Therefore, for all recorded green light phases and for all lanes and intersections the quotient was calculated by dividing the time elapsed from the beginning of the green light until the moment the last vehicle had passed through before the yellow (amber) light. Therefore, the used green light time was calculated (maximum value $=1.00$ - in case the green light time is used without time losses by the vehicles to pass through). Based on previous surveys conducted in the School of Rural and Surveying Engineering of the Aristotle University of Thessaloniki, the calculated average time of headways (using the methodology proposed and described by Transportation Research Board (2010)) was equal to $2.12 \mathrm{sec}$.

Making the assumption that using this value for all the intersections, a theoretical maximum number of vehicles that could pass through per lane/per leg/per intersection was calculated, it was then possible to compare these values to the number of vehicles that actually passed through based on the results of the field surveys.

The next step of the analysis concerned the calculation of an average value of headways for all 20 green light time periods (phases) per lane/ per intersection leg as a representative value. An assumption was made in an effort to identify those vehicles that did not create congestion phenomena. Therefore, those vehicles presenting headway over $3.00 \mathrm{sec}$ were excluded from the next phase of the analysis. Specifically, three criteria were implemented to the collected data:

The lanes analyzed were those which either served only through movements or all possible combinations, through and right or/ and left turning movements.

The average value of headway per lane per intersection leg for all 20 green light time periods (phases) was lower than $3.00 \mathrm{sec}$.

The theoretical number of vehicles that could pass through per green light time period (phase) divided by the number of vehicles passed through during the field surveys should be lower than or at the best case equal to 1.00 .

As a result, the number of collected data was reduced to 4,019 headways concerning 11 (out of 27) at-grade 
signalized intersections and 16 lanes. These values formed the sample, which was finally analyzed in the second phase of the data analysis.

Based on the above, the new sample was analyzed in order to identify the values which could be normally distributed or not. This was the first test in order to identify if these values could be part of the analysis or systematic faults were hiding in them. Fig. 1 presents the results of this first analysis (Median value $=2.26 \mathrm{sec}$ and Standard Deviation $=1.32 \mathrm{sec}$ ).

After analyzing the results, it was clear that those headway values above $3.00 \mathrm{sec}$ had to be excluded and the normal distribution should be calculated again in order the sample to be normalized. The final sample was then reduced to 3,379 values for which the median value was equal to $1.84 \mathrm{sec}$ and the standard deviation was equal to $0.59 \mathrm{sec}$ (Fig. 2).

By calculating the average value of headways (following the guidelines of Transportation Research Board (2010) according to which the time intervals of the four first vehicles should be ignored) for the final sample, it then became possible to calculate the values of Prevailing Saturation Flow Rates, using Eq. (2):

$s_{i}=3600 / h_{i}$,

where:

- $s_{i}=$ Prevailing Saturation Flow Rate,

- $h_{i}=$ Headways' Average Value according to Transportation Research Board (2010).

1st Attempt Calculating Normal Distribution

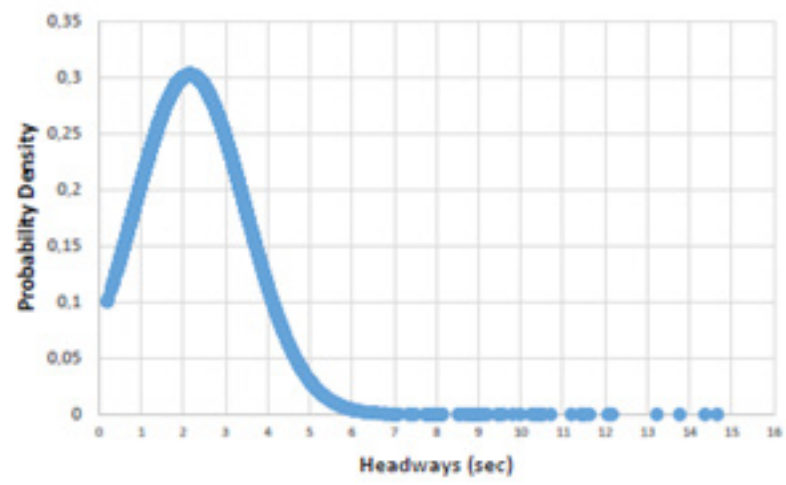

Fig. 1 First attempt of calculating Normal Distribution

2nd Attempt Calculating Normal Distribution

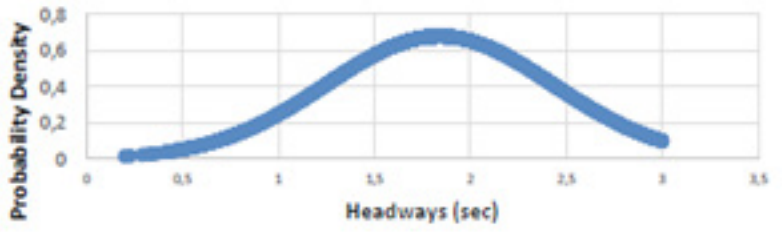

Fig. 2 Second attempt of calculating Normal Distribution
The following step was to calculate the Adjusted Saturation Flow Rates using Eq. (3) (Transportation Research Board, 2010):

$$
\begin{aligned}
& s=s_{o} * N * f_{w} * f_{H V} * f_{g} * f_{p} * f_{b b} \\
& * f_{a} * f_{L U} * f_{L T} * f_{R T} * f_{L p b} * f_{R p b} * P H F .
\end{aligned}
$$

It must be noted that the PCE value used for these calculations was the average value of parameter $E_{t}$ (described above) and specifically $E_{t}=2.18$. By comparing the calculated values for those lanes which were primarily identified as fully congested, it was made clear that this choice was correct as for the majority of them (13 out of 16) the ratio between Prevailing over Adjusted Saturation Flow was over 1.00 .

\section{Conclusions}

The methodology developed and described in the present paper revealed that it is possible to calculate the PCE value for commercial vehicles following a new approach. Furthermore, although the calculated value (average value of the fully congested lanes) of PCE was 2.18 for the study area, which is close to the official value that is used in Greece, that is 2.00, it can produce significant impacts to a transportation study, where the volume of commercial vehicles is high.

The proposed methodology requires the minimum equipment for the field surveys, however it requires significant number of surveyors (equal to the number of the lanes under study at each intersection) in order for the process to provide the most reliable and solid results possible, especially when compared to the methodology described and proposed by Transportation Research Board (2010).

Furthermore, although the developed methodology requires a "one shot" surveying process, since no video is recorded as in the Transportation Research Board (2010) process for an in house analysis, provides the ability to the observers to have better viewing to the lanes under study since they are free to be positioned wherever they think they could have better view. It must be mentioned at this point that the Transportation Research Board (2010) methodology cannot do the same without using cutting-edge technology and/or equipment for video recording (i.e. drones or elevated video cameras).

However, the research team acknowledges that the proposed methodology needs to be tested in the field more than one time in order to fully identify and describe any weaknesses and problems. The results of the above-mentioned methodology could be the basis for further research (not only for the city of Thessaloniki) due to the fact that the PCE value differentiates for each case study. Finally, according 
to the calculated PCE value and its difference from the official value used in Greece, it seems that the developed methodology should be followed in the framework of each transportation study, regardless of the space and the time of

\section{References}

Al-Kaisy, A. F., Hall F. L., Reisman E. S. (2002) "Developing passenger car equivalents for heavy vehicles on freeways during queue discharge flow", Transportation Research Part A: Policy and Practice, 36(8), pp. 725-742. https://doi.org/10.1016/S0965-8564(01)00032-5

Cunagin, W. D., Chang, E. C. P. (1982) "Effects of Trucks on Freeway Vehicle Headways Under Off-Peak Flow Conditions", Transportation Research Record: Journal of the Transportation Research Board, 869, pp. 54-59. [online] Available at: http:// onlinepubs.trb.org/Onlinepubs/trr/1982/869/869-009.pdf [Accessed: 10 March 2020]

Demarchi, S. H., Setti, J. R. (2003) "Limitations of Passenger-Car Equivalent Derivation for Traffic Streams with More Than One Truck Type", Transportation Research Record: Journal of the Transportation Research Board, 1852(1), pp. 96-104. https://doi.org/10.3141/1852-13

Greenshields, B. D., Shapiro, D., Ericksen, E. L. (1947) "Traffic Performance at Urban Street Intersections", In: Traffic Quarterly, Eno Foundation for Transportation, Westport, CT, USA, pp. 254-269. Available at: https://babel.hathitrust.org/cgi/pt?id=pst.000013472177\&view=1up \&seq=4 [Accessed: 10 March 2020]

Huber, M. J. (1982) "Estimation of Passenger-Car Equivalents of Trucks in Traffic Stream", Transportation Research Record: Journal of the Transportation Research Board, 869, pp. 60-70. [online] Available at: http://onlinepubs.trb.org/onlinepubs/trr/1982/869/869-010.pdf [Accessed: 10 March 2020]

Kimber, R. M., McDonald, M., Hounsell, N. (1985) "Passenger car units in saturation flows: Concept, definition, derivation", Transportation Research Part B: Methodological, 19(1), pp. 39-61. https://doi.org/10.1016/0191-2615(85)90028-1

Krammes, R. A., Crowley, K. W. (1986) "Passenger Car Equivalents for Trucks on Level Freeway Segments", Transportation Research Record: Journal of the Transportation Research Board, 1091, pp. 10-17. [online] Available at: http://onlinepubs.trb.org/ Onlinepubs/trr/1986/1091/1091-002.pdf [Accessed: 10 March 2020]

Ljubicic, H., Pavlovic, J. (2015) "Urban Logistics Systems and Night Goods Delivery", In: 2nd Logistics International Conference, Belgrade, Serbia, pp. 321-326. the implementation, the fact that traffic conditions change (traffic volumes, traffic density, speed of vehicles, in some cases green light time, traffic distribution, etc.) produces the necessity of constantly updating the PCE value.

Mallikarjuna, C., Rao, K. R. (2006) "Modelling of passenger car equivalency under heterogeneous traffic conditions", In: 22nd ARRB Conference: Research into Practice: Proceedings, Canberra, ACT, Australia, pp. 1-13.

Municipality of Thessaloniki (2016) "Municipal Council's Decision No. 125", Municipality of Thessaloniki, Thessaloniki, Greece.

Praveen, P. S., Arasan, V. T. (2013) "Influence of Traffic Mix on PCU Value of Vehicles under Heterogeneous Traffic Conditions", International Journal for Traffic and Transport Engineering, 3(3), pp. 302-330. https://doi.org/10.7708/ijtte.2013.3(3).07

Rahman, M. M., Nakamura, F. (2005) "Measuring Passenger Car Equivalents for Nonmotorized Vehicle (Rickshaws) at Mid-Block Sections", Journal of the Eastern Asia Society for Transportation Studies, 6, pp. 119-126. https://doi.org/10.11175/easts.6.119

Seguin, E. L., Crowley, K. W., Zweig, W. D. (1982) "Passenger Car Equivalents on Urban Freeways", U.S. Department of Transportation, Offices of Research and Development, Washington, DC, USA, Rep. FHWA/RD-81/156.

Skabardonis, A., Dowling, R., Kiattikomol, V., Safi, C. (2014) "Developing Improved Truck Passenger Car Equivalent Values at Signalized Intersections", Transportation Research Record: Journal of the Transportation Research Board, 2461(1), pp. 121-128. https://doi.org/10.3141/2461-15

St. John, A., Glauz, W. D. (1976) "Speeds and Service on Multilane Upgrades", Transportation Research Record 615, Transportation Research Board, National Research Council, Washington, DC, USA, pp. 4-9. Available at: http://docplayer.net/162294622Speeds-and-service-on-multilane-upgrades.html [Accessed: 10 March 2020]

Transportation Research Board (2010) "HCM2010 Highway Capacity Manual", Transportation Research Board, Washington, DC, USA.

Werner, A., Morrall, J. F. (1976) "Passenger Car Equivalencies of Trucks, Buses, and Recreational Vehicles for Two-Lane Rural Highways", In: 55th Annual Meeting of the Transportation Research Board, Washington, DC, USA, pp. 10-17. Available at: http://onlinepubs.trb.org/Onlinepubs/trr/1976/615/615-003.pdf [Accessed: 10 March 2020] 